\title{
ARTES Y ARTISTAS EN LA OBRA DE PARDO BAZÁN: CUENTOS Y ÚLTIMAS NOVELAS
}

\author{
Yolanda Latorre \\ Universidad de Lérida
}

\begin{abstract}
RESUMEN
Para conocer la literatura del siglo XIX es imprescindible una experiencia con la producción de Emilia Pardo Bazán, la cual está insertada en la crisis de valores finisecular. En este artículo, se busca reconocer la intervención de las artes plásticas o musicales en los aspectos discursivos y formales de los textos pardobazanianos, para relacionar esta narrativa con el género "novela de artista".
\end{abstract}

\section{ABSTRACT}

Experiencing Emilia Pardo Bazán' writing is essential to really know XX century literature. Her production is embedded in the turn-of-the-century value crisis. This article aims at recognizing the intervention of fine arts and music in the formal and discoursive features of her texts, in order to relate this narrative to the genre known as "artist's novel".

Podemos constatar, sin reparos, que la obra de Emilia Pardo Bazán, se erige como un documento imprescindible para conocer la literatura del siglo XIX. Su producción, desafortunadamente, todavía no goza de las atenciones críticas otorgadas a otros de sus coetáneos, aunque este desacierto está siendo subsanado poco a poco.

Estudiar las complejidades de Emilia Pardo Bazán como narradora madura, es conocer a una creadora cuya obra se inserta en la crisis de valores propia del cambio de siglo. Es fundamental, para ello, precisar la presencia de las artes -plásticas o musicales- en sus textos, sobre todo de 1890 a 1921, año de su muerte. Tanto sus grandes novelas del siglo XX: La Quimera (1905), La Sirena negra (1908) y Dulce Dueño (1911), como muchos de sus cuentos o su novela inédita Selva (1913), manifiestan haberse enriquecido con las aportaciones de cada una de las artes. Por un lado, las artes intervienen en los aspectos discursivos y formales, muy renovadores; por otro, relacionan a doña Emilia con el género narrativo de raíz romántica llamado "novela de artista", que trata los avatares artístico-vitales de los creadores de arte.

\section{La presencia de las artes}

Las artes intervienen decisivamente en la obra de la Pardo Bazán madura. Las referencias artísticas que pueblan sus textos son fruto, en parte, de sus experiencias biográficas. 
Doña Emilia viajó constantemente por Europa, actividad plasmada en unas crónicas repletas de referencias artísticas como Al pie de la Torre Eiffel (1889) o Cuarenta días en la Exposición (1900). Tanto sus libros de viaje como su obra crítica son claves imprescindibles para interpretar la aparición de ciertos nombres o títulos, puesto que podemos ya anunciar que la escritora anheló siempre la unión de lo artístico (en todas sus facetas) con lo vital. Sirva de ejemplo su alusión al famoso Gante, El Cordero Místico (1902): "Cuando uno (...) acaba de contemplar en El Haya la Lección de anatomía de Rembrant, ya no cree que la pintura le reserve grandes sorpresas" (Pardo Bazán 1891-1922: 99-110).

En cuanto referencia artística, es inevitable aludir a uno de los pintores preferidos de la condesa: Francisco de Goya. Surgió en su famosa conferencia "Goya y la espontaneidad española", de 1905, y es cita constante en sus obras de ficción.

Sería interminable exponer aquí la lista de referencias artísticas recogidas por Pardo Bazán, puesto que las hay pictóricas, musicales, escultóricas, arquitectónicas o sobre artes decorativas. Sintetizando, diremos que la pintura es el arte más aludido por la escritora, y que destacan los lienzos de temática religiosa o pintores como Goya, El Greco, Velázquez, Murillo, Van Dick y los prerrafaelistas, al lado de los sensualismos de un Rubens o un Watteau. Le sigue en importancia la música -cuyo centro de atención es Wagner-y, después, la imaginería escultórica barroca. Todo ello la confirma como más "romántica" que "clásica" -valga la síntesis-, conciliadora y de vastas perspectivas artísticas.

Pardo Bazán está plenamente enraizada en la tradición filosófico-literaria del sincretismo entre artes y literatura. Es un rasgo acentuado gradualmente a lo largo de su carrera, aunque no ha sido apenas estudiado. No obstante, a nuestro parecer, merece la atención especial que han gozado otros autores del XIX; estamos pensando, por ejemplo, en el excelente trabajo del profesor Peter Bly para Galdós (Bly 1986). El caso de doña Emilia es sorprendente si se examina con celo su discurso lingüístico de madurez, porque tiende a imitar la carga semántica propia del código de las artes, plásticas y musicales. Se trata del fenómeno denominado "transposición artística": el traslado de cualquier valor conceptual o estructural de otras artes a los fragmentos literarios.

Una descripción hallada en La Sirena Negra (1956: 912), por ejempo, nos evocará la imagen de una determinada obra de arte: "Mi meditación se convertía en cavilación visionaria. Acaso dormía, acaso deliraba. El alcaloide del café concentrado actuaba sobre mi sistema nervioso, y con malsano goce dejé volar mi fantasía, provista de unas alas membranosas, gris oscuro, de murciélago, que acababan de brotarle"; es el Capricho de Goya. El sueño de la razón produce monstruos, pero todavía va más lejos, llega a "contarnos" fragmentos de cuadros. Citaremos uno procedente de un lienzo del pintor Wiertz, por quien no sentía gran simpatía: "El último cañón, la carne de cañón; Napoleón ardiendo en los infiernos, rodeado de espectros que oprimiendo a los débiles figurados por un gigante brutal, un Polifemo que con sus patazas aplasta a los compañeros de Ulises..." (1905: 856). Doña Emilia incluso se atreve a describir, aun a riesgo de resultar excesivamente explícita, un lienzo completo. Es el caso de uno de sus cuadros preferidos, El Cordero Místico, de Van Dick, cuya composición, centrada hacia el motivo del Cordero-Dios, simboliza la desorientación espiritual del pintor Silvio Lago'

La condesa evocará la música, asimismo, en discursos plenos de lirismo. Así lo recoge su cuento Fantasía, la Nochebuena en el Limbo (1892: 316): “(..)y de su masa confusa brotaba 
un coral análogo a los de Wagner, en que el llanto estrepitoso, el gemido desconsolado, la carcajada, el berrinche, el pataleo, el gorjeo, se unían en un solo acorde estridente, irónico, arrancado a las cuerdas y a los metales de infernal orquesta", o Silvio Lago, el pintor protagonista de La Quimera (1905: 884): "Raudales de poesía bucólica le brotaban del alma, y su sentimiento exquisito le hacía saborear, no sólo el cuadro, sino el plañidero toque de oración que suspendía la oración campestre. Es la nota de Millet". Los modelos formales de la condesa proceden, en su mayor parte, de la literatura francesa parnasiana y simbolista y de la "écriture artiste" (Miterrand 1987) hallada en Zola, los Goncourt o Beudelaire.

La sensibilidad de la Pardo, moderna, mucho debe a los Goncourt. Tras descubrir su poder plástico calificándolos de "padres del impresionismo" por "inventar expresiones pintadas", comentó su dominio de la trasposición: "De los Goncourt procede el naturalismo, el impresionismo, la "transposición" de los procedimientos de un arte a otro, de la pintura y la música a la literatura; la transformación de la prosa, y la enfermedad nerviosa como tema de arte" ${ }^{\prime 2}$. Esta influencia, de hecho, marcará su carrera. La cuentística de doña Emilia abarca buena parte del cambio de siglo, desde 1866 a 1921. Durante estos años, además, escribe sus tres últimas novelas. Son más de cincuenta años durante los cuales es lógico que se produzca una tranquila evolución narrativa, sobre todo en el caso de una escritora voluntariamente empapada de las últimas modas literarias.

Cada una de las artes constituirá un área cuyo interés no será meramente descriptivo, sino esclarecedor del universo estético y cultural pardobazaniano, aunque la plasticidad pictórica es esencial en doña Emilia -pintora aficionada-, con especial intensidad en su madurez. Esta plasticidad caracteriza la visión de muchos de sus protagonistas (entre los cuales destacan, lógicamente, los pintores): en ciertos momentos sobresalen miradas, de algún modo con sensibilidad pictórica hacia diversos objetivos.

Se trata de una narración del siglo XX consciente de que los viejos métodos descriptivos, deterministas, psicológicos, resultan insuficientes para expresar las situaciones del hombre dentro del mundo. Se cambia el enfoque narrativo, se asimilan nuevas concepciones humanas, y se exige menos de la anécdota. Existen muchas ocasiones para comprobarlo, como el cuento de 1891, "Las tapias del camposanto" (I: 996): "En Marineda no se le había ocurrido a nadie que fuese bonita Clara y, en realidad, no lo era sino vista su figura al través de la imaginación excitada por recuerdos artísticos y convencionalismos estéticos", o el caso del decadente Gaspar Montenegro, protagonista de La sirena negra (1908: 924): "Mañana las siluetas de estos dos seres, en mi espíritu, quedarán borradas de la pizarra con una esponja...". Desde luego, la percepción del creador posee un grado de esteticismo potente, como una fe interior que se sobrepone a la calidad del universo contemplado.

La condesa se informó en Nordeau de las ideas de Ruskin o Rosetti, y conoció a los pintores del XV en las obras de Peladan ${ }^{3}$. Pintura y literatura actuarán como fenómenos psicológicos que se explican mutuamente, según sus propias afirmaciones: “...mi concepto del arte está influido, fatalmente, sin que para eso haya remedio, por los ideales literarios. Siempre veré, detrás de una obra de arte, un concepto, un pensamiento, un símbolo y una manifestación más o menos clara y expresiva de algo cerebral, superior a los sentidos y a la mera reproducción de la realidad sensible" (Pardo Bazán 1900: 138). Esta afirmación puede ejemplificarse con uno de sus estilos pictóricos más recurrentes desde El saludo de las brujas 
(1987), la figuración prerrafaelista. Los prerrafaelistas la inspiran siempre, incluso aparecen en su novela inédita Selva. En esta novela habla, por ejemplo, de la actitud "evidentemente prerrafaelesca" de Bice, la protagonista (1913: 3). El prerrafaelismo será, en fin, la culminación espiritual en la trayectoria del pintor Silvio Lago, en La Quimera (1905). La pintura, además, plasma el mundo interior en la narrativa pardobazaniana. Esto se observa en ciertos autorretratos, entre los cuales se cuentan el de Lina Mascareñas, en Dulce Dueño (1911: 962) o el de La Sirena Negra (1908: 877). Son ciertos individuos perceptivos, preparados estéticamente y convertidos en símbolos de la crisis finisecular.

En todo caso, la plasticidad de doña Emilia está marcada rotundamente por la estética de la luz. Recordemos, si no, sus comentarios en La Revista Compostelana de Santiago, durante los años 1876 y $1877^{4}$, disertando extensamente sobre el calórico, la luz y la electricidad, y desmenuzando los fenómenos visuales: “(...) La luz, en efecto, es el verdor de los campos y el brillante matiz de las flores, la diafanidad opalina de los celajes de otoño (...) la fugitiva halagüeña ondulación de la línea y del contorno, la Venus de Milo, la Dánae del Tiziano, la forma en fin". Y no olvidemos sus manifestaciones en una conocida carta a Menéndez Pelayo: "es en mí cosa inevitable, condición de mi temperamento, ver antes que todo el color." (Menéndez Pelayo 1983: 482-3).

Al final de su carrera, la condesa intensifica una tendencia en relación a la pintura o escultura: describe piezas pictóricas y escultóricas, y estas descripciones se confunden con las de individuos descritos mediante tecnicismos plásticos, lo cual los equipara en verosimilitud narrativa. Ocurre, por ejemplo, en La Sirena Negra: "Más ahincadamente que antes fijé mi lupa en el joven ayo. Empecé por desmenuzar su tipo físico. Debe de proceder de familia hidalga (...) porque tiene las manos delicadas, largas de dedos, como las de ciertos retratos del Greco" (1908: 904) o en Selva (1913: 24-25) donde surge una cara "como tallada en materia recia y resistente, de algunos retratos de antaño".

La descripción de objetos decorativos revela, más bien, una tendencia simbolista de doña Emilia, que indaga en el alma de las cosas, pero es significativo cómo ciertos individuos de vacuidad interior son tratados como si de objetos se tratara, en el caso de la frívola Espina Porcel, en La Quimera (1905). En conexión con todo esto, el fenómeno del coleccionismo afecta personalmente a la Pardo, quien se erige defensora del patrimonio artístico e informa de su estado en el fin de siglo, en parte a través de las colecciones de sus amigos Romualdo Nogués presente en La Quimera- y Lázaro Galdiano, cuyas obras de arte pueblan sus narraciones5.

\section{Los artistas plásticos en las narraciones pardobazanianas}

La idiosincrasia del creador de arte, en Emilia Pardo Bazán, contextualiza sus relatos en la corriente de las "novelas de artista" -prácticamente no estudiada en Europa- cuyo centro es el creador de las obras artísticas. La denominación "novela de artista" (Künstlerroman), existe desde fechas relativamente recientes. H. Marcuse (1922) la propuso para un tipo de narrativa alemana, iniciada en el "Sturm und Drang", cuyos héroes -y artistas- eran el centro en torno al cual se construía su época. Más tarde, Th. R. Bowie y M. Beebe estudiarían el papel del artista en la ficción novelesca francesa, inglesa y alemana a finales del siglo XIX y principios del XX, y A. W. Phillips revisaría una serie de novelas hispanoamericanas (1885-1916) con acusado 
relieve del artista como héroe, o bien como personaje menor. Para R. Gutiérrez Girardot, la problemática del creador inserto en una sociedaad burguesa determinará, en fin, las tramas de estas narraciones; precisamente, el advenimiento de la era burguesa (entre 1789 y 1830), según F. Calo Serraller, coincide con el éxito de este tema y el de la novela como género por excelencia, cobijo de artistas cuyas reflexiones dan paso a la modernidad. Es conveniente advertir, en todo caso, los lazos de esta parcela narrativa con las pautas arquetípicas del modelo novelístico "de aprendizaje" (Bildungsroman) o "de evolución" (Entwicklungsroman) ${ }^{6}$.

El tipo literario del "artista" -sea músico o creador plástico- está familiarizado con el poeta, el "escritor" o el "intelectual". Son antiprosaicos, marginales, su vida es arte y su arte es religión; rasgos que cuajan bien en narraciones de discurso heterogéneo, que tienden al intimismo. La leyenda del artista, además se nutrió de huellas griegas y cristianas que marcaron su propensión autodestructiva, común también en dandis y bohemios, locos o héroes castigados (Prometeo, Filoctete, Dédalo), mártires identificados con la pasión de Cristo en el XIX, etc. ${ }^{7}$

Lo que podríamos denominar, genéricamente, "novelas de artista", ha sido conformado por obras relevantes, algunas de ellas de influencia significativa para la tradición narrativa española de la pasada centuria. Ejemplos de ineludible consideración en la literatura alemana lo constituyen el Wilhelm Meisters Lehrjahre (1795) de J. W. Goethe, Lucinde de F. Schlege o, entre los franceses, Le Cheuf d'oeuvre inconnu (1831) y Gamabra (1837) de H. de Balzac y Scènes de la vie de bohème de Murguer ${ }^{8}$. En la literatura norteamericana sobresale la obra de H. James, en particular, Roderick Hudson, aunque la lengua inglesa nos otorga una novela fundamental, J.Joyce y $A$ portrait of the artist as a young man (1916). Pero para España será decisiva la influencia francesa de los Goncourt (Manette Salomon, 1867), J-K Husymans (A rebours, 1884) o Zola (L'ouvre) ${ }^{9}$.

Las constantes de los franceses marcarán la novelística peninsular. Esta mostrará, en consecuencia, la plasmación de la vida del pintor y el reflejo de la sociedad del momento en medio de discusiones de estética, ataques al arte establecido, visitas a salones y exposiciones y aparición de figuras artísticas o literarias de la época. El protagonista se ve envuelto, frecuentemente, en asuntos sentimentales, a menudo son también críticos o periodistas y no es extraño que la novela constituya un "roman à clef". Numerosos poemas, cuentos o incluso piezas dramáticas -el teatro romántico escogía artistas de los Siglos de Oro- acogen la problemática del creador de belleza. Las vicisitudes de éste, en especial el tipo “ artista plástico", transcurren en narraciones que hemos hallado ámbito perfecto para las "transposiciones artísticas", aquellas descripciones influenciadas por las artes con un amplio espectro de funciones en los relatos. Abundantes cuentos españoles del cambio de siglo participan, asimismo, de los rasgos propios de los relatos de $\operatorname{artistas}^{10}$.

Una muestra de "novela de artista"" en España -de finales del XIX a principio del XXrevela cómo las artes son adaptadas por escritores de fines del siglo XIX, y cómo parece definirse una especial atención por el artista plástico (pintor) conforme se aproxima nuestra centuria. Aún así, los novelistas interpretarán, individualmente, las funciones del artista o de otros individuos cuyos rasgos mantienen con él ciertas concomitancias: estetas, coleccionistas, bohemios o intelectuales. Dicha propensión evidencian E. Pérez Escrich en El frac azul (1864), o las novelas Fra Filippo Lippi (1877) de E. Castelar y Doña Berta (1891) de L. Alas. Podríamos añadir Tristana (1892) de Galdós o La maja desnuda (1906) de V. Blasco Ibáñez; Pérez de Ayala con Troteras y danzaderas o Tinieblas en las cumbres (1907), o Las tardes del 
sanatorio (1909) de Silvio Kossti, pero la lista sería interminable. Recordemos la novela del 98: El mundo es ansí (1912) de Pío Baroja, A.Gavinet o Azorín, e incluso los protagonistas estetas de Valle Inclán o la novela de Ricardo León, Casta de hidalgos (1915) ${ }^{12}$.

Las líneas narrativas pardobazanianas, en relación con las "novelas de artista", manifiestan una destacada deuda con los maestros galos. Doña Emilia crea artistas plásticos modernos en búsqueda de belleza total por influencia de los Goncourt, estetas hipersensibles y solitarios como los Huysmans, o pintores -pensemos en La Quimera- al modo zolesco, destruidos en busca de la cuentística; con especial intensidad desde 1891, exhibe creadores idealistas como símbolos del héroe contemporáneo parangonables a mártires, santos o Cristos en busca de un ideal. Los cuentos de doña Emilia, en ocasiones antecedentes preparatorios de las grandes novelas, ofrecen tres líneas básicas: los problemas entre el artista enfermizo, esteta antiburgués o artesano y una rígida sociedad -por ejemplo en Otro añito (1909), Por el arte (1891), El torreón de la esperanza (1898), La zurcidora (1918) o Doradores (1912), el genio y la locura del creador hallado en Entre razas (1898), El contador (1901) o La risa (1907), y la dicotomía entre arte y vida, ética o estética, como sucede en Recompensa (1904), La Edad de Oro (1920) o El Cinco de Copas (1893) ${ }^{13}$.

El motivo del creador en doña Emilia se define con precisión en las novelas del siglo XX -en parte, desde El saludo de las brujas (1897)-. El esteta de La sirena negra (1897) -novela macabra, goyesca, decadente-, simboliza el hallazgo de la verdad en el mundo contemporáneo. Sus luchas religiosas interiores, introspección o misticismo se explicitan por medio de lo plástico, castizo o europeísta, un rasgo definitivo de la Pardo Bazán madura presente también en Dulce Dueño (1911), historia de conversión de una esteta perturbada por la frivolidad contemporánea. Manifiesta la máxima pardobazaniana de compaginar lo sensible (el Arte) con lo inteligible, el sensualismo -propio de la misma Pardo Bazán- con el misticismo.

Pero La Quimera es la genuina novela del pintor. De base biográfica, trata la evolución estético-vital del artista rodeado de colegas -el tipo bohemio, dandi, pintor vendido...- amigo de intelectuales y coleccionistas y amante de mujeres perniciosas, y que persigue un ideal. Representa todas las polaridades propias del artista con dejos decadentes, heredero del romanticismo francés y, en conjunto, se erige como símbolo de ciertas facetas de la compleja problemática anímica finisecular. La condesa propone aquí la solución ético-estética: el Arte como camino de salvación por el catolicismo, algo que niega a su protagonista para, pensamos, magnificar el "exemplum". Además, predomina la focalización introspectiva, combinada con un lirismo y una mirada plástica que llega a componer "lienzos". Por otro lado, el arte está implicado en las uniddes semánticas de la obra y en la propia trayectoria de Lago, representante de las tensiones básicas de la novela : realismo / idealismo, antiguo / moderno, naturaleza / artificio, heroísmo / decadencia, materia / espíritu.

Lo plástico, en La Quimera, va marcando las pautas tanto de las perversiones decadentes -no hay conversión completa por parte de Silvio $\mathrm{Lago}^{14}$-, como de la idea de salvación y la concepción dualista del hombre en materia y espíritu -la obsesiva presencia de Cristos-. El mensaje pardobazaniano es definitivo. Sin rechazar las aportaciones del arte y la cultura contemporáneas, ofrece alternativas que se inclinan por la coexistencia de Arte y Vida, recurriendo al artista como héroe, individuo adecuado para transmitir su propio concepto de la existencia en la modernidad. 
Incluso en la última novela -prácticamente desconocida- de Pardo Bazán, la acción de las artes y la presencia de individuos perceptivos y contempladores adquiere relevancia. Ignacio Selva es eỉ protagonista de esta novela homónima, inédita, de Emilia Pardo Bazán, que podría ser calificada de policíaca o detectivesca, aunque, en la tradición de Arsène Lupin o Rocamboles, debe no poco a la novela de folletín ${ }^{15}$. La fábula de esta narración está sustentada por ciertos objetos artísticos que la nutren hasta el punto de que condicionan irremisiblimente su transcurso; éstos son las joyas y, ante todo, un Cristo de considerable valor, robados. Destaquemos, además, la presencia de un protagonista calificado con ciertas peculiaridades de los estetas amantes de la belleza, inserto en un universo de aristócratas y coleccionistas.

La existencia de Selva fue anunciada por Benito Varela Jácome y, en ciertas cuartillas custodiadas en la casa-museo de la condesa, N. Clemessy realizó una estructuración de la misma $^{16}$. El contenido de la novela es el siguiente: Selva, escéptico y cosmopolita, manifiesta su talante de curioso observador al pasear por delante del teatro Apolo y recordar cómo, tras la sesión, tuvo la oportunidad de conocer a los frívolos Teplitz, barones húngaros, y a su hija Bice. Inaugura doña Emilia la narración de forma paralela a La Sirena Negra, publicada seis años atrás, pues hallábamos a Gaspar Montenegro callejeando por Madrid tras asistir a una representación en el mismo teatro; aunque Gaspar, que manifiesta un hastío vital en cierto grado presente en Selva, buscará el ámbito de una iglesia para sus meditaciones. Poco después, Selva se encuentra con el coleccionista Chaves y con el príncipe de Flandes. El arte y las joyas de la Teplitz y el famoso robo de La Gioconda adquieren relevancia, mientras se roba un valioso crucifijo al coleccionista. Termina la novela abierta con las pesquisas de Bice para descubrir pruebas concretas de los recientes robos.

Datada en 1913, Selva nos recordará a alguno de los estetas de la cuentística pardobazaniana, particularmente al pesimista Gaspar Montenegro o en algunos momentos a Lina, de Dulce Dueño (1911), sobre todo por su sensación de náusea o de vacío existencial, aunque sin la acusada vaguedad de algunas novelas de folletín ${ }^{17}$. Un aparato firme de citas o referencias artísticas aproxima a Selva a la configuración de la novela de los estetas o de los artistas: "La Cibeles, -sobre la limpidez del cielo- /adquiría/ un aspecto aristocrático, como de monumento romano; /una vaguedad elegante, latina*/ (p. 2). Es lo escultórico, por otro lado, uno de los motivos impulsores de los espacios descriptivos. Selva contempla a Bice transponiéndola en materia propia para la escultura, convertida ésta en un medio cualificador: -A la pregunta, subió un -corto lampo de vergüenza rosada a las mejillas marmóreas de -/Bice/, y, haciéndose la desentendida, contestó: -¿Cómo? ¿Que no se pone sus -/esmeraldas/? (p. 6). Pero es el Cristo robado lo que desencadena una red de acciones en la novela. El sospechoso, por otra parte, puede sujetarse a la calificación de Selva aplicada al ladrón de la Gioconda, un "estético egoísta" (p. 28), un maniático y tenaz coleccionista tachado de "aficionado vanidoso" (p. 28).

No es extraño que se le dedique una descripción transpositiva al crucifijo, parangonable a las halladas en otros relatos de la condesa, como La Quimera (p. 26), o que en joyas u objetos hermosos puedan ser convertidos incluso los propios individuos (p. 62). La colaboración de las artes visuales en el medio descriptivo parece esencial, como sucede en aquella imagen de "la belleza -/original de Bice modernista" (p. 8), o prerrafaelista, calificada de "arcangelito" (p. 8). La imagen visualizada sobresale, pues, explicitada al máximo, observemos un ejemplo: "La 
rápida marcha del artilugio /desvaneció, como/ película de cinematógrafo, toda aquella cordialidad, pero Selva -/quedó parado/-" (p. 4). La escritora se esmera en la elección del léxico descriptivo y no vacila en substituir o tachar lo inconveniente, reacción apreciada en el cotejo de algunos fragmentos procedentes de las dos versiones. Otros instantes de la narración evidencian las imágenes no en fragmentos descriptivos, sino en la vivacidad del diálogo: “-Viendo que Selva maniobraba hacia el extremo del banco, -/Bice cambió de aspecto. A su altivo enojo sucedió una- desbordante angustia y, suplicante, murmuró: /Ella cambió de expresión instantáneamente, recobrando la de las madonas quinientistas, que se veían en iglesias Cartujas italianas pintadas sobre fondo de oro... No se aparte, Selva! No me deje sola... (p. 8).

Muchas de estas escenas llegan al lector a través de la retina de Selva, portador de imágenes estáticas que, por la sucesión manifestada en la red del discurso narrativo, constituyen un efecto cinematográfico. No fue ajena doña Emilia a los avances de esta industria, experimentada en España desde 1896. El lenguaje de las imágenes de Selva es parangonable al del cine mudo, por su ponderación gestual y atención a la imagen como significante privilegiado, cuando aquel sólo contaba con los dos últimos registros, el de la imagen propiamente dicha y el de la imagen de la palabra, aparte del ocasional acompañamiento musical, lo que se ha denominado "signo analógico compuesto". En Selva pueden advertirse, además, "enfoques" o "primeros planos" -normalmente de objetos valiosos- cuya conexión temporal con las demás partes de la acción es indefinida o indiferente, y que se encuentra a veces fuera del tiempo dramático. Tengamos en cuenta, asimismo, que la velocidad y el movimiento son sujetos de investigación de las primeras vanguardias, a cuyos presupuestos no era ajena la condesa, quien consideraba iconoclastas y revolucionarios a aquellos "cadetes futuristas que tienen por capitán a Marinetti y por cuartel su revista Poesía", aunque hallaría en ellos "temas del pasado, que cada vez se confunden más con el presente"18.

Los ojos de este detective son focos esteticistas cuya funcionalidad narrativa ha resultado, en definitiva, superior a las circunstancias misteriosas propias de las ágiles novelas policíacas. Doña Emilia, pues, se ha servido de este tipo de individuos y del Arte -interesada por él desde siempre-, sometiendo su obra a una pausada evolución que culmina en su madurez, imbricándola mediante estrategias modernas y otorgándole unas perspectivas temáticas propias del fin de siglo, todo ello para expresar las complejidades del mundo contemporáneo.

\section{Notas}

1. Tanto la crítica como la ficción pardobazanianas (1851-1921) están determinadas por sus conocimientos y gustos artísticos.

J. Paredes Núñez. 1990. Cuentos completos. La Coruña: Galicia Editorial; Pardo Bazán E. 1957. La Quimera, Obras completas. Madrid: Aguilar; 1956, La Sirena Negra, Ibid, II; Dulce Dueño, Ibid. Abreviaturas: Obras completas (OC), La Quimera (LQ), La Sirena negra (LSN), Dulce Dueño (DD), Selva (S). La Quimera ha sido estudiada recientemente por Daniel S. Whitaker. 1988. "La Quimera de Pardo Bazán y la literatura finisecular". Madrid. Pliegos.

2. OC, III, p. 953; E. Pardo Bazán. 1891. La España Moderna, III, XXVII, 15 marzo, pp. 68-94; E. Pardo Bazán. 1911. La literatura francesa moderna. La transición, p. 270.

3. OC, III, pp. 1291, 1295 y 936. También pp. 1186 y 956. 
4. 1876. "Artículos sobre ciencia amena”, Año I, Santiago, 16 Octubre, n.3; 1876. "La ciencia amena”, p.18; 1876. "La ciencia amena", año I, Santiago 24 de Noviembre, n. 8, p. 57; 1876 . "La luz", 1 Diciembre, n. 9 , p. 65. 1876. "La luz", 9 Diciembre, n. 10, VII; 1876. "La luz", 16 Diciembre, p. 81, VIII; 1877. "La circulación del movimiento", año II, 9 Enero, p. 105, n. 14; 1877. Enero, n. 13, p. 97; 1877, año II, 9 Enero, n. 14; p. 104. Todos los datos proceden de las revistas aquí mencionadas.

5. Recogemos algunos de estos datos en Y. Latorre. 1989. "El coleccionismo como fenómeno finisecular: Romualdo Nogués y E. Pardo Bazán”, Cuadernos de Estudios Borjanos, XXI-XXII, pp. 236-246; 1990. "La colección Lázaro Galdiano y su relación con Romualdo Nogués y E. Pardo Bazán, Goya, 216, MayoJunio, 331-335; 1993-1994. "El retablo del Cordero Místico, de Van Dick, símbolo espacio-vital en La Quimera, de Pardo Bazán, Cuaderno de Estudios Gallegos, t. XLI, n. 6; 1996. "Las citas de arte en E. Pardo Bazán, una muestra del canon artístico en la narrativa del siglo XIX", Boletín del museo e instituto "Camón Aznar", LXIII (105-120); "Femineidad estetizada: sensualidad y misticismo en la figuración escultórica de Pardo Bazán”, Scriptura, Universitat de Lleida, en prensa.

6. Herbert Marcuse. 1985. Il "romanzo dell'artista" nella letteratura tedesca, Torino: Einaudi. Maurice Beebe. 1964. Ivory Towers and Sacred Founts (The artists as Hero in Fiction from Goethe to Joyce), New York University Press; T:R: Bowie. 1950. "The painter in French Fiction", University of North Carolina Studies in romance Languages and Literatures, 15, pp. 1-60. Allen W. Phillips. 1983. Temas del modernismo hispánico y otros ensayos, Madrid: Gredos, p. 54; Rafael Gutiérrez Girardot. 1983. Modernismo, Barcelona: Montesinos, p. 54. F. Calvo Serraller. 1990. La novela del artista, Madrid: Mondadori, y 1990. "La pintura narrada", Claves, Julio/Agosto, 54-65.

7. Ernst Kris y Otto Kurz. 1982. La leyenda del artista, Madrid: Cátedra, 1982, pp. 19-25. R. Panofsky, F. Saxl. 1991. Saturno y la melancolía, Madrid: Alianza, p. 12. E. Neumann. 1986. Mitos de Artista (Estudio psicohistórico sobre la creatividad), Madrid: Metrópolis, pp. 53-112. Sobre el pintor-poeta. D. Scott. 1988. Pictorialist Poetics (Poetry and the visual arts in nineteeth-Century France), Cambridge: Cambridge University Press, pp. 1-50.

8. J. W. Goethe. 1840. Wilhelm Meisters Lehrjahre (1795-1796) (Goethe's sämmtliche Werke in füng Bäden, Paris: Baudry (I. Paul Renouard, III). F. Schlegel. 1963. Lucinde, en Romantiques allemands, Dijon: Gallimard, Bibliothèque de la Pléyade, pp. 521-608. H. de Balzac. 1981. Le Chef d'uvre inconnu. Gambara, Massimilla Doni, Paris: Flammarion E. Murguer. 1988. Scènes de la vie de bohème (1848) (Paris: Gallimard). Roderick Hudson fue escrita en 1874 y publicada en 1875 (1969. Middlesex: Penguin).

9. James Joyce. 1969. A portrait of the artist as a young man, Heineman: London. Edmond et Jules de Goncourt. 1979. Manette Salomon (1867) (París: Union générale d'editions). Publicada en 1884 (1975. Paris. Union Générale d'Editions). L'Oeuvre (1886). 1967. Oeuvres Complètes, V, Paris: ed. du Seuil. Para los artistas dentro del teatro, véase Susana Vedovato Ciaccioa, "Los artistas en las tablas. Trayectoria de un tema en la época romántica”, vv. aa. 1984. Teatro Romántico Spagnolo (Bologna: Patron , pp. 163-177).

10. Puede aclarar el concepto el volumen Transpositions, actes du Colloque National organisé à l' Úniversité de Toulouse- Le Mirail. 1986. 15-16 mai. Nombraremos solo, por problemas de espacio, ciertos casos relevantes como el de J. Dicenta en Un divorcio (1893) y Un autor al uso (1894), Azorín en Bohemia (1897), Fragmento, Paisajes o Envidia. También el especialista en artistas plásticos J.O. Picón, autor de Confesiones (1892) o La cuarta virtud (1892), los artistas de M. Bueno en Celedonio Bernal (1895), El retrato o Vanidad (1902), los del incisivo E. Zamacois en El ideal (1897) o Junto al fuego (1900), o los desengañados y solitarios de L. Alas en Un documento (1882), Rivales (1892) o Vario (1892). Tenemos siempre en cuenta los preceptos comparatistas de C. Guilén (1985). Lo uno y lo diverso, Barcelona: Crítica.

11. Véase el análisis temático de M. A. Ezama para los relatos breves del XIX, 1992. El cuento de la prensa y otros cuentos (Aproximación al estudio del relato breve entre 1890 y 1900), Zaragoza: Prensas Universitarias.

12. E. Pérez Escrich. 1864. El frac azul (Episodios de un joven flaco), Manini Hnos. Ed.: Madrid; E. Castelar Ripoll. 1877-1879; Fray Filippo Lippi (Novela histórica), Barcelona: Emilio Oliver y Compañía (1879 (2a ed.), tomos 2 y 3, de 1877 ( $1^{a}$ ed)); L. Alas, "Clarín". 1980. Doña Berta, en Cuentos, Superchería, 
Cuervo, Doña Berta, prólogo de Ramón Pérez de Ayala, Madrid: Taurus, pp. 133-201; B. Pérez Galdós. 1971 ( $^{\text {a }}$ ed.). Tristana, OC, Madrid: Aguilar; V. Blasco Ibáñez. 1967. La maja desnuda OC, t. I. La catedral, (op. cit, pp. 30-1069); R. Pérez de Ayala. 1986. Tinieblas en las cumbres, Madrid: Castalia; Silcio Krossti. 1981. Las tardes del sanatorio, Zaragoza: Guara; Pío Baroja, El mundo es ansí, ed. de Leonardo Romero Tobar. 1986. Barcelona: Plaza y Janés, pp. 50-54; Ricardo León. 1915. Casta de hidalgos, Obras Completas, II, Madrid: Raoul Peant.

13. Véase Paredes, op. cit.

14. Estamos de acuerdo con M. Hemingway -entrañable investigador pardobazaniano, fallecido recientementecuando señala que Arte y Vida no llegan a congeniar en la novela de 1905. Véase 1989. "Pardo Bazán and the Rival Claims or Religion and Art”, BHS, 66, 1989, pp. 241-50.

15. B. Varela, Jácome (1973. "Estructuras novelísticas de E. Pardo Bazán”. Cuadernos de Estudios Gallegos. Santiago de Compostela, pp. 121-23) estudia los rasgos finiseculares de esta novela.

16. Basándonos en el trabajo de N. Clémessy en la Real Academia Gallega, expondremos, a continuación, algunas de sus informaciones en la presentación de la novela. Las notas procederán siempre de la VA. Transcribiremos los fragmentos de Selva con los símbolos: - (tachadura), * (palabra ilegible), negrita y cursiva (palabra tachada y sustituida a mano), /Palabra entre barras/ (palabra a mano, tras tachadura ilegible).

17. Varela Jácome anota el atentado contra Alfonso XIII en Abril de 1913, hecho reseñado por la propia autora en una de sus crónicas de La vida contemporánea. Además, se cita a Tita Ruffo, a quien doña Emilia dedica una crónica a principios de 1913 (Véase Clémesy, op. cit.). Parece ser que su asunto tiene algo que ver con el famoso robo de La Gioconda, el 20 de Agosto de 1911. En las dos versiones del capítulo III, se da el hecho como reciente, aludiendo doña Emilia el misterio que seguía rodeando las circunstancias del robo también en sus crónicas de La Ilustración Artística (1911, 1553, p. 638). Se escribió, por consiguiente, Selva — considerada novela corta- y se abandonó su redacción, entre finales de agosto de 1913 y principios de diciembre del mismo año (Véase, también, Clémessy, op. cit., p. 11). En el trabajo de 1975. "Emilia Pardo Bazán et le conte rural”, Paris: Mélanges offerts à Charles Vincent Aubrun, I, pp. 191200), Clémessy estudia la fascinación de Pardo Bazán entre el misterio, desapariciones o crímenes, además de su tendencia a contar historias trágicas, sobre todo ambientadas en los cuentos rurales gallegos. Véase también A Clarke. 1973. "Doña Emilia Pardo Bazán y la novela policíaca", Boletín de la Biblioteca Menéndez Pelayo, 49, 1973, pp. 375-91).

18. Para el signo, Antonio Monegal. 1993. Luis Buñuel de la literatura al cine (Una poética del objeto), Barcelona: Anthropos, p. 116. En cuanto al futurismo, E. Pardo Bazán, OC, III, p. 1492.

\section{Bibliografía}

Alas, Leopoldo. 1980. "Doña Berta”. Cuentos, Supechería, Cuervo, Doña Berta. Madrid: Taurus.

Balzac, Honoré. 1981. Le Chef d'oeuvre inconnu, Gamabara, Massimilla Doni. Paris: Flammarion.

Baroja, Pío. 1986. El mundo es ansí. Barcelona: Plaza y Janés.

Blasco Ibáñez, Vicente. 1967. La maja desnuda, Obras completas. Madrid: Aguilar.

Bly, Peter. 1986. Vision and the visual arts in Galdós. Liverpool: Cairus. 
Beebe, Maurice. 1964. Ivory Towers and Sacred Founts (The Artist as Hero in Fiction from Goethe to Joyce). New York University Press.

Bowie, Theodore Robert. 1950. "The painter in French Fiction”. University of North Carolina Studies in Romance Languages and literatures, 15.

Castelar Ripoll, Emilio. 1877 . Fray Filippo Lippi (Novela histórica). Barcelona: Emilio Oliver y Compañía.

Calvo Serraller, Fernando. 1990. La novela del artista. Madrid: Mondadori.

1990. "La pintura narrada”. Claves. Julio-Agosto: 54-65.

Clémessy, Nelly. 1975. "Emilia Pardo Bazán et le conte rural”. Mélanges offerts à Charles Vincent Aubrun. Paris: 191-200.

Clarke, Anthony. 1973. "Doña Emilia Pardo Bazán y la novela policíaca". Boletín de la Biblioteca Menéndez Pelayo. 49: 375-91.

Ezama, María de los Ángeles. 1992. El cuento de la prensa y otros cuentos (Aproximación al estudio del relato breve entre 1890 y 1900). Zaragoza: Prensas Universitarias.

Goethe, Johann Wolfang von. 1849. Wilhelm Meisters Lehrjahre Goethe's sämmtliche Werke in füngf Bäden. Paris: Baudry (I. Paul Renouard, III).

Goncourt, Esmomd et Jules de. 1979. Manette Salomon. París: Unión générale d’editions.

Guillén, Claudio. 1985. Lo uno y lo diverso. Barcelona: Crítica.

Gutiérrez Girardot, Rafael. 1983. Modernismo. Barcelona: Montesinos.

Hemingway, Maurice. 1989. "Pardo Bazán and the rival Claims or Religion and Art". BHS. 66: 241-50.

James, Henry. 1969. Roderick Hudson. Middlesex: Penguin.

Joyce, James. 1969. A portrait of the artist as a young man. Heineman: London.

Klibansky, R., E. Panofsky y F. Saxi. 1991. Saturno y la melancolía. Madrid: Alianza.

Krossti, Silvio. 1981. Las tardes del sanatorio. Zaragoza: Guara.

Kris, Ernst y Otto Kurz. 1982. "El coleccionismo como fenómeno finisecular: Romualdo Nogués y E. Pardo Bazán”. Cuadernos de Estudios Borjanos. XXI-XXII: 236-46. 
Latorre, Yolanda. 1990. "La colección Lázaro Galdiano y su relación con Romualdo Nogués y E. Pardo Bazán”. Goya. 216, Mayo-Junio: 331-35.

1993-1994. "El retablo del Cordero Místico, de Van Eyck, símbolo espacio-vital en La Quimera, de Pardo Bazán”. Cuaderno de Estudios Gallegos. XLI, 6.

1996. "Las citas de arte en Emilia Pardo Bazán, una muestra del canon artístico en la narrativa del siglo XIX.". Boletín del Museo e Instituto "Camón Aznar". LXIII: 105-20.

"Femineidad estetizada: sensualidad y misticismo en la figuración escultórica de Pardo Bazán." Scriptura. Universitat de Lleida. En prensa.

León, Ricardo. 1915. Casta de hidalgos, Obras completas. Madrid: Fundación Universitaria Española.

Miterrand, Henry. 1987. Le regard et le signe. Paris: PUF.

Monegal, Antonio. 1993. Luis Buñuel de la literatura al cine (Una poética del objeto). Barcelona: Anthropos.

Murguer, E. 1988. Scènes de la vie de bohème. Paris: Gallimard.

Neumann, E. 1986. Mitos de artista (Estudio psicohistórico sobre la creatividad). Madrid: Metrópolis.

Pardo Bazán, Emilia. 1956. La Sirena Negra, Obras completas. Madrid: Aguilar.

1956. Dulce Dueño, Obras completas. Madrid: Aguilar.

1957. La Quimera, Obras completas. Madrid: Aguilar.

1891-1922. Por la Europa Católica, Obras completas. Madrid: Renacimiento.

1891. La España Moderna. XXVII: 15 marzo.

1911. La literatura francesa moderna. La transición, Obras completas. Madrid: Renacimiento.

1900. "Crónicas y cuadros". La Ilustración Artística. 948.

1911. "El robo de la Gioconda". La ilustración Artística. 1553: 638.

Paredes Núñez, Juan. 1990. Cuentos Completos. I-IV. La Coruña: Galicia Editorial. 
Pérez de Ayala, Ramón. 1986. Tinieblas en las cumbres. Madrid: Castalia.

Pérez Galdós, Benito. 1971. Tristana, Obras compleas. Madrid: Aguilar.

Pérez Escrich, E. 1864. El frac azul (episodios de un joven flaco). Madrid: Manini Hnos.

Phillips, Allen. 1983. Temas del modernismo hispánico y otros ensayos. Madrid: Gredos.

Schlegel, Friedrich. 1963. Lucinde en Romantiques allemands. Dijon: Gallimard, Bibliothèque de la Pléyade.

Scott, David. 1988. Pictorialist Poetics (Poetry and the visual arts in nineteenth-Century France). Cambridge: Cambridge University Press.

Transpositions. 1986. Actes du Colloque National organisé à l'Université de Toulouse-Le Mirail, 15-16 mai.

Varela Jácome, Benito. 1973. Estructuras novelísticas de E. Pardo Bazán. Santiago de Compostela: Cuadernos de Estudios Gallegos.

Vedovto Ciaccia, Susana. 1984. "Los artistas en las tablas. Trayectoria de un tema en la época romántica”. Teatro Romántico Spagnolo. Bologna. Patron.

Whitaker, Daniel . 1988. "La Quimera" de Pardo Bazán y la literatura finisecular. Madrid: Pliegos.

Zola, Emile. 1967. L'Oeuvre. Oeuvres Complètes. Paris: du Seuil. 
